\title{
GESTÃO ESCOLAR: CONTEXTO E CONSTRUÇÃO
}

\author{
Elisangela Aparecida Bulla |keshoji ${ }^{1}$, Adriana Aparecida de Lima Terçariol ${ }^{2}$ \\ ${ }^{1}$ Doutoranda em Educação pela Universidade Nove de Julho (UNINOVE). Professora da Educação Básica, Técnica e \\ Tecnológica da área de Gestão, no Instituto Federal de Educação, Ciência e Tecnologia de São Paulo - IFSP, Campus \\ Birigui. E-mail: elisangela.bulla@gmail.com \\ ${ }^{2}$ Doutora em Educação e Currículo pela Pontifícia Universidade Católica de São Paulo - PUC-SP. Professora e \\ Pesquisadora no Programa de Pós-Graduação em Educação - PPGE e Mestrado em Gestão e Práticas Educacionais - \\ PROGEPE na Universidade Nove de Julho - UNINOVE.
}

\section{RESUMO}

O presente estudo se constitui como um recorte da pesquisa intitulada "Gestão na Perspectiva do Diretor e de Docentes: Estudo de Caso em uma Instituição Pública de Ensino Profissional e Tecnológico", desenvolvida junto ao Programa de Pós-Graduação em Educação da Universidade do Oeste Paulista UNOESTE/SP. O principal objetivo do estudo aqui apresentado foi identificar e analisar como o diretor da instituição pública da rede federal de ensino profissional e tecnológico compreende a gestão escolar. A pesquisa caracteriza-se numa abordagem qualitativa, no formato estudo de caso. $O$ instrumento para coleta de dados centrou-se na entrevista semiestruturada. $O$ processo de buscas nas bases de dados teve como objetivo levantar o que já existia de produções científicas sobre gestão escolar. Por isso, utilizou-se dos conhecimentos produzidos nos textos obtidos, a partir do levantamento de publicações científicas, desenvolvidas no Brasil, nos últimos 19 anos, entre 2000 e 2018, na base de dados do Scielo (Scientific Electronic Library Online) e na base de dados do IBICT (Instituto Brasileiro de Informações em Ciência e Tecnologia). Esses dados foram articulados com os dados obtidos na entrevista realizada com o diretor de uma instituição pública da rede federal de ensino profissional e tecnológico. Os principais resultados evidenciaram que a gestão escolar pautada numa gestão democrática não é compreendida como um processo acabado, mas em construção, visto que as ações pedagógicas que ocorrem no contexto escolar estão ainda em processo.

Palavras-chave: Gestão Escolar. Diretor Escolar. Gestão Democrática.

\section{SCHOOL MANAGEMENT: CONTEXT AND CONSTRUCTION}

\section{ABSTRACT}

The present study constitutes a cut of the research titled "Management in the Director's and Teachers' Perspective: Case Study in a Public Institution of Professional and Technological Education", developed with the Post-Graduation Program in Education of the Universidade do Oeste Paulista - UNOESTE / SP. The main objective of the present study was to identify and analyze how the director of the public institution of the federal network of professional and technological education comprises the school management. The research is characterized in a qualitative approach, in the case study format. The instrument for data collection, semi-structured interview. The search process in the databases had as objective to raise what already existed of scientific productions on school management. Therefore, we used the knowledge produced in the texts obtained, based on the survey of scientific publications developed in Brazil in the last 19 years, between 2000 and 2018, in the Scientific Electronic Library Online database and at the base of IBICT (Brazilian Institute of Information in Science and Technology). These data were articulated with the data obtained in the interview with the director of a public institution of the federal network of professional and technological teaching. The main results showed that school management based on 
democratic management is not understood as a finished process, but under construction, since the pedagogical actions that occur in the school context are still in process.

Keywords: School Management; Management Models; Democratic Management.

\section{GESTIÓN ESCOLAR: CONTEXTO Y CONSTRUCCIÓN}

\section{RESUMEN}

El presente estudio constituye un recorte de la investigación titulada "La gestión en la perspectiva del director y los docentes: estudio de caso en una institución pública de educación profesional y tecnológica", desarrollado con el Programa de Posgrado en Educación de la Universidade do Oeste Paulista. - UNOESTE / SP. El objetivo principal del presente estudio fue identificar y analizar como el director de la institución pública de la red federal de educación profesional y tecnológica comprende la gestión escolar. La investigación se caracteriza en un enfoque cualitativo, en el formato de estudio de caso. El instrumento para la recolección de datos se centró en la entrevista semiestructurada. El proceso de búsqueda en las bases de datos tenía como objetivo plantear lo que ya existía de las producciones científicas sobre la gestión escolar. Por lo tanto, utilizamos el conocimiento producido en los textos obtenidos, en base a la encuesta de publicaciones científicas desarrolladas en Brasil en los últimos 19 años, entre 2000 y 2018, en la base de datos en línea de la Biblioteca Electrónica Científica y en la base IBICT (Instituto Brasileño de Información en Ciencia y Tecnología). Estos datos se articularon con los datos obtenidos en la entrevista con el director de una institución pública de la red federal de enseñanza profesional y tecnológica. Los principales resultados mostraron que la gestión escolar basada en la gestión democrática no se entiende como un proceso terminado, sino en construcción, ya que las acciones pedagógicas que ocurren en el contexto escolar todavía están en proceso.

Palabras clave: Gestión escolar. Director de la escuela. Gestión democrática.

\section{INTRODUÇÃO}

A administração escolar tem sua história construída nas diferentes escolas de administração de empresa e nos modelos como configuração social construída ou em construção (PARENTE, 2017). Porém, a escola deve ser compreendida pela sua particularidade e especificidade, por isso deve ter um modelo de gestão adequado à sua realidade, visto que trabalha com seres humanos e sua formação. Sendo assim, os princípios da administração empresarial não podem ser assimilados nas atividades da escola.

[...] o processo de construção do ambiente escolar e da educação deve ir além da assimilação de técnicas de administração que garantam sua eficiência, porque a organização escolar apresenta objetivos distintos daqueles vividos pelas empresas e, por esta razão, necessita de uma construção teórica própria, capaz de abarcar seus problemas e sua especificidade (MAIA, 2008, p. 32).

Nessa perspectiva, o termo gestão será utilizado no decorrer deste trabalho, por considerar que vai ao encontro do que Maia (2008) propõe quanto à questão das relações horizontalizadas: a coletividade, a participação e a descentralização. Também será associado à gestão o termo escolar, porque as atividades do diretor fazem parte da gestão escolar. Do mesmo modo, compreendemos a gestão como democrática, num contexto escolar que pressupõe ter suas especificidades e características próprias.

Entende-se que, de acordo com a concepção que o diretor tem sobre a gestão escolar é que irá articular o desenvolvimento das 
atividades escolares. Portanto, nessa concepção serão norteadas suas ações como diretor, o seu papel, as maneiras de participação requerida, tanto da sua parte, como da comunidade escolar.

Nesse sentido, o objetivo deste estudo foi identificar e analisar como o diretor da instituição pública da rede federal de ensino profissional e tecnológico compreende a gestão escolar.

Sendo assim, a seguir, apresenta-se o método adotado para o encaminhamento desta análise, para, posteriormente, abordar a temática a partir de aspectos considerados relevantes nos estudos levantados, a partir de buscas em bases de dados, articulando-os às teorias e documentos da área, bem como com excertos de falas coletadas de um diretor de uma instituição pública da rede federal de ensino profissional e tecnológico. Por fim, algumas considerações são apresentadas.

\section{MÉTODO}

Visando alcançar o objetivo proposto, a pesquisa caracteriza-se numa abordagem qualitativa, no formato estudo de caso. Lüdke e André (1986, p. 18-20) mencionam que o estudo de caso possui características fundamentais como: a) "visam à descoberta"; b) "enfatizam a interpretação em contexto"; c) "buscam retratar a realidade de forma completa e profunda"; d) "usam uma variedade de fontes de informação"; d) "revelam experiência vicária e permitem generalizações naturalísticas".

O desenvolvimento deste estudo pautouse também no levantamento de estudos realizados na área "Gestão Escolar" e se desencadeou a partir de uma busca de publicações científicas produzidas nos últimos 19 anos, entre 2000 e 2018, que discutem a temática proposta. A busca ocorreu nas bases de dados: Scielo (Scientific Eletronic Library Online) e IBICT (Instituto Brasileiro de Informações em Ciência e Tecnologia), justifica-se a escolha por essa base de dados, devido estar disponível aos usuários, com acesso aberto, online, possibilitando o acesso a textos completos publicados em periódicos brasileiros, abrangendo várias áreas do conhecimento e diversas revistas indexadas. Como descritores, utilizou-se os termos: "Gestão Escolar" e "Dimensões Gestão Escolar". Além da consulta nessas bases, foram levantadas legislações e bibliografias que abordam o tema "Gestão Escolar".

O processo de buscas nas bases de dados teve como objetivo levantar o que já existia de produções científicas sobre gestão escolar. Sendo assim, procedeu-se a leitura dos resumos, tanto dos artigos como das dissertações e teses, para posteriormente escolha dos documentos que versam sobre a temática em análise. Após a leitura do material selecionado e estudos mais aprofundados, avançou-se para a sistematização das ideias encontradas. Vale salientar ainda que, as análises aqui apresentadas foram enriquecidas e articuladas aos depoimentos coletados, em entrevista semiestruturada, de um diretor atuante em uma instituição de ensino profissional e tecnológico, sendo um servidor ocupante de cargo efetivo da carreira docente, conforme menciona a Lei no 11.892 (BRASIL, 2008). Vale apontar que a instituição escolar referenciada possui apenas um diretor. Com relação ao material coletado junto aos docentes, ele foi publicizado em outra produção científica ${ }^{1}$.

A pesquisa foi submetida à apreciação da Comissão de Ética em Pesquisa da Universidade do Oeste Paulista - UNOESTE, recebendo parecer favorável para sua execução (CAAE: 37780414.6.0000.5515).

\section{GESTÃO ESCOLAR: O PAPEL DO DIRETOR}

A gestão escolar entendida como a relação do diretor com suas atividades e a contribuição destas para a organização do trabalho escolar utiliza-se, diferentemente, da atividade administrativa enquanto concepção puramente técnica. Segundo Paro $(2000$, p. 123) a atividade administrativa "é condição necessária da vida humana, estando presente em todos os tipos de organização social". No entanto, é necessário desvelar as especificidades dos conteúdos técnicos em cada contexto, segundo os objetivos pretendidos.

De fato, na medida em
que a prática da
administração escolar é
tratada do ponto de vista
"puramente" técnico são
omitidas as suas
articulações com as
estruturas econômica,
política e social,
obscurecendo a análise
dos condicionantes da
educação. As normas
técnico-administrativas
que são propostas como
normas desses

${ }^{1}$ Colloquium Humanarum, vol. 14, n. Especial, Jul./Dez. 2017, p. 404-411. ISSN: 1809-8207. DOI: 10.5747/ch.2017.v14.nesp.000972 
condicionantes. No entanto, elas são adotadas e implementadas como se fossem autônomas, isentas das determinações econômico-sociais (FÉLIX, 1986, p. 82).

É urgente sair da condição conservadora da ordem social vigente, da postura acrítica, romper com o pensamento da existência de uma neutralidade técnica da administração capitalista, quando na prática se reproduz na escola tal teoria. Neste sentido, a Administração Escolar pode revestir-se de um caráter transformador, na medida em que, indo contra os interesses de conservação social, contribui para instrumentalização cultural das classes trabalhadoras (PARO, 2000, p. 129).

Sendo assim, as atividades do diretor, numa gestão escolar democrática, é compreendida como:

o desenvolvimento de algumas competências inseparáveis entre si e em termos hierárquicos: competência técnica, competência política e competência pedagógica. Há a presença de um forte compromisso com a comunidade, com o desenvolvimento do trabalho coletivo na escola e com o elemento docente presente na atividade do diretor (MAIA, 2008, p. 39).

Nota-se nas palavras do diretor da instituição ${ }^{2}$, abordada nesta pesquisa, ao mencionar o que entende por gestão escolar:

[...] entendo que ela deva abranger parte de infraestrutura e a parte educacional. A gestão escolar é ampla. 0 docente deve estar com a mente bem aberta, para poder receber as orientações, participar de cursos, dos encontros, estar reformulando

\footnotetext{
${ }^{2}$ Busca-se apoiar as análises, aqui desenvolvidas, sobre a gestão escolar, articulando-as com as concepções do diretor da instituição da rede federal de ensino profissional e tecnológica, participante desta investigação.
}

sempre suas aulas, sempre se atualizando, através de cursos. Ter uma formação em mestrado, doutorado, mas isso não dá ao docente uma condição de dar aula de fato com qualidade, ele tem que ter formação pedagógica, para ele poder conseguir conhecer as metodologias que ele poderia usar para ele mesmo melhorar. (DIRETOR_R, 2015).

Os debates críticos na educação brasileira têm favorecido repensar e ressignificar a realidade, que encaminha ao processo de transformação de caraterísticas cognitivas na comunidade escolar. Tal interferência altera os alicerces de sentido e significado na gestão escolar. Consequentemente, oferece-se possibilidades para a mobilização do coletivo organizado. Nesse sentido, o sistema de gestão participativa dispõe de elementos que melhor contribuem com os debates educacionais e vislumbra alternativas de mudanças (CORREIA, 2011).

Corrobora Bastos e Santos (2018, p. 92) que "é conveniente que a gestão escolar acompanhe e contribua para/com a prática do professor, por meio de uma escuta atenta, de modo a promover atividades de formação continuada que atendam aos anseios e às necessidades do grupo." Nessa perspectiva, segue a fala do diretor:

[...] todo o corpo docente deve estar bem preparado $e$ afinado com o serviço sócio pedagógico e aberto às críticas, quando tiver algum problema, para que possam resolver problema de aula, ele possa se envolver com o serviço sócio pedagógico e ter orientações que possam melhorar [...] a qualidade do ensino e aprendizagem dele que é importante (DIRETOR_R, 2015).

Entende-se que é o elemento docente que, ao desenvolver suas atividades, se faz presente na atividade do diretor e, por consequência, na comunidade escolar, atingindo 
diretamente o estudante, conforme menciona Maia (2008), sobre as competências inseparáveis do diretor. Na fala do diretor, percebe-se ainda a sua preocupação e desafio quanto à questão do docente ter uma formação pedagógica, não somente a formação técnica. Esse aspecto se traduz no excerto apresentado a seguir:

[...] ele tem que ter
formação pedagógica,
para ele poder conseguir
conhecer as metodologias
que ele poderia usar para
ele mesmo melhorar.
Porém, a falta de
formação pedagógica, em
concursos anteriores era
obrigatório a fazer a
formação de acordo com o
edital agora nem é mais.
Principalmente quando
você é engenheiro, você
tem uma dificuldade muito
grande de assimilar a
formação pedagógica, os
conteúdos, os nomes,
entender toda aquela. [...]
você não gosta muito
disso, porque você é mais
físico, matemático,
químico. Então quando
começa a falar em
determinadas [...] algumas
palavras você não
consegue entender aquilo
é difícil entender, então às
vezes você não aproveita
muito o curso, você acaba
agindo segundor sua
formação mais dura e não
olha tanto para a parte
mais pedagógica, isso
dificulta. (DIRETOR R,
2015).

Ser docente é buscar, constantemente, refletir sua ação, o que propicia sua formação (PIMENTEL, 1998; PIMENTA; GHEDIN, 2006). Consequentemente, favorece sua melhor atuação e participação para contribuir no processo de ensino e aprendizagem. Como menciona Schön (1997, p. 85), “o grande inimigo da confusão é a resposta que se assume como verdade única". E, de modo muito oportuno, o autor ainda comenta o caso de um docente que levou muito tempo para constatar que estava reprovando cinquenta por cento dos seus alunos, quando então reflete que deve haver meios mais eficazes para assegurar maior sucesso aos estudantes. A importância da formação continuada mencionada fica explícita na fala do diretor, a seguir:

[...] o docente deve estar
com a mente bem aberta,
para poder receber as
orientações, participar de
cursos, dos encontros,
sempre sutar
reformulando às suas
aulas, sempre se
atualizando, através de
cursos. (DIRETOR R, 2015).

Sabe-se que a gestão escolar não é neutra, por isso deve-se compreender sua intencionalidade política, pedagógica e educacional. O que requer do papel do diretor provocar reações de toda a sua equipe para o enfrentamento dos desafios da escola, sendo essas importantes para que objetivos educacionais sejam alcançados (GARCIA et al. 2016). A valorização das relações entre todos os envolvidos nesse ambiente escolar deve ser, primordialmente, considerada, uma vez que é na diversidade que as ações são articuladas com vistas ao propósito maior (MARTINS; SOUSA, 2012; GONÇALVES; FRANÇA, 2013; CARVALHO, 2014; FERNANDES; CAMPOS, 2015; GALVÃO; SADOYAMA, 2017).

"Portanto, destaca-se o papel da gestão como provocadora de espaços e tempos, mediadora e propulsora para que esse processo aconteça, trabalhando coletivamente com autoridade, responsabilidade e iniciativa." (BASTOS; SANTOS, 2018). Aspectos esses evidenciados na fala do diretor. E assim, entendese que cabe à gestão escolar compreender o docente enquanto elemento presente na atividade do diretor, a importância da formação continuada proporcionado aos docentes reflexões sobre seus saberes, impactando em ações que favoreçam essencialmente o aluno. Tal aspecto é abordado no Plano Nacional da Educação 2014-2024, o qual apregoa que a formação continuada deve ser realizada constantemente, pois se trata de aperfeiçoamento necessário para o exercício da profissão docente (BRASIL, 2015).

\section{GESTÃO PEDAGÓGICA E ADMINISTRATIVA}

A gestão pedagógica é a dimensão da gestão escolar mais importante, a espinha dorsal. Todas as atividades convergem para ela, visto 
que está diretamente envolvida com a mobilização de ações e atividades para promover o processo de ensino e aprendizagem, voltado para a formação cidadã, conforme corrobora o diretor, sujeito da pesquisa, ao mencionar: [...] o comprometimento com a educação, evidentemente, o seu fim é formar estudantes. (Diretor R, 2015).

Para que o trabalho pedagógico se desenvolva nesse sentido, compete ao diretor conduzir ações que propiciem mudança de mentalidade de todos os membros da comunidade escolar. Aspecto que pode ser percebido quando o diretor menciona:

[...] o campus avançou
bastante, estamos
melhorando ainda mais o
planejamento, as ações
pedagógicas, justamente
para o docente sentir a
importância dele. A falta
de comprometimento é
um desafio (DIRETOR R,
2015).

A mudança implica participar da escola, num processo de conquista diária, deixando de lado o preconceito de que a escola pública é apenas um aparelho burocrático do Estado capitalista, que visa, meramente, a questões administrativas (GADOTTI, 1997; MENEZES, 2009).

Um caminho para desfazer e transformar a realidade pode estar no Projeto PolíticoPedagógico (PPP), conforme aponta Galvão e Sousa (2012), a partir de um de seus estudos, no qual contaram com a participação de cinco diretores de escolas técnicas do Sistema Único de Saúde $^{3}$. Esse estudo apontou que o PPP é um documento essencial para organizar e estruturar as instituições de ensino, sempre com vistas à sustentabilidade. Os diretores dessas instituições buscaram incorporar princípios de gestão, dentre eles, a descentralização da decisão, com a participação de todos, em todos os níveis da instituição.

No entanto, na escola, objeto desta pesquisa esse documento estava em construção, no período em que este estudo foi desenvolvido.

\footnotetext{
${ }^{3}$ São instituições públicas criadas ou "recriadas", num contexto de redemocratização da sociedade brasileira, a partir de 1980 para qualificar/formar os trabalhadores de nível fundamental e médio empregados no SUS que não possuíam qualificação específica para as funções que desempenhavam. Em seu Regimento Escolar as características de uma escola visando a integração ensino-serviço.
}

A Lei de Diretrizes e Bases da Educação Nacional (LDB) no 9.394/96, menciona que a construção desse documento deve contar com a participação dos docentes (BRASIL, 1996), da mesma maneira, tal concepção é abordada no Plano Nacional de Educação 2014-2024 (BRASIL, 2015). Esse documento é um balizador da missão, visão e valores da escola, assim como o tipo de formação que se acredita e almeja, sendo a identidade da instituição (GARCIA et al., 2016).

Por melhores que sejam os processos administrativos de gestão escolar, se não visam produzir resultados efetivos de melhoria da aprendizagem dos estudantes, sua aplicação não faz sentido.

[...] se o estudante tem
acesso ao coordenador ou
o coordenador é uma
pessoa acessível de fato,
ele vai apresentar o
problema, esse problema
pode ser apresentado
através de uma ocorrência
diretamente para o
coordenador e o
coordenador vai, se reúne
com o docente pra tentar
de fato ver o que
realmente está
acontecendo, e tomar as
providências em nível de
coordenadoriar
(DIRETOR_R, 2015).

Sua fala expressa ainda que o princípio do comprometimento com a escola é intrínseco à atividade do diretor e de toda a comunidade escolar:

[...] ter comprometimento, zelar pelo bem público, tem uma série de coisas que você tem que seguir, isso é natural, mas não significa que você está seguindo aquilo ali, você está atingindo os objetivos de um ensino $e$ aprendizagem de qualidade, tem que ter apoio pedagógico, das áreas, do diretor, dos gerentes, coordenadores (DIRETOR_R, 2015).

Segundo Aguiar (2008), o Conselho Escolar vem responder a uma demanda histórica dos educadores e movimentos sociais, com vistas 
à gestão democrática, em atendimento a uma concepção de participação efetiva, comprometida e responsável. Complementa Garcia et al. (2016, p. 91) o Conselho Escolar trata-se de uma instância, "um colegiado que envolve a descentralização do poder, trazendo a legitimidade às ações do diretor."

O Conselho Escolar da instituição federal de ensino profissional e tecnológico, ainda não existia, no contexto investigado, mas já estava agendada a primeira reunião para o segundo semestre de 2015. No entanto, na Resolução $n^{\circ}$ 11, de 27 de março de 2014, estabelecem-se as diretrizes para sua implementação. De acordo com a referida resolução, o Conselho Escolar, denominado de Conselho de Campus (CONCAM) possui caráter normativo, consultivo e deliberativo, sendo órgão máximo do campus, composto pelo: diretor; gerente administrativo; gerente educacional; no mínimo um e no máximo cinco representantes de docentes; no mínimo um e no máximo cinco representantes de estudantes; no mínimo um e no máximo cinco representantes de técnico-administrativos; dois representantes da sociedade civil (um representante do setor público designado pela Secretaria de Educação do Município e um representante de pais de estudantes) (SÃO PAULO, 2014).

Sendo assim, é necessário apreender aspectos que podem contribuir para leitura e releitura de propostas conceituais, para que em ações práticas seja possível superar ou diminuir a dicotomia que existe entre a gestão administrativa e pedagógica.

De fato, precisamos de concepções e atitudes que subvertam o cotidiano burocrático da escola, para podermos pensar e agir de maneira ambiciosa, capaz de realizar mudanças verdadeiras que venha do potencial instituinte dos sujeitos que fazem a escola acontecer e não só de mudanças anunciadas por leis, decretos e, principalmente, pelo uso político da educação e da escola (FORMIGA, 2007, p. 121).

Por isso, no contexto complexo das dimensões da gestão escolar e, principalmente, na gestão administrativa que tanto se critica, os estudos apresentam que a sua contribuição é vista segundo a concepção que se tem da escola. Ao superar as questões administrativas quando estas se voltam para atender ao objetivo educacional, assim como quando é possível perceber elementos de uma gestão democrática, as possiblidades do novo, da transformação, poderão vir a ser. Portanto, conforme o artigo 3 ㅇ da LDB no 9.394/96 "o ensino será ministrado com base nos seguintes princípios:" dentre eles “a gestão democrática." (BRASIL, 1996).

\section{GESTÃO DEMOCRÁTICA E PARTICIPATIVA}

No artigo 14 da LDB no 9.394/96 menciona-se que "os sistemas de ensino definirão as normas da gestão democrática do ensino público na educação básica, de acordo com as suas peculiaridades [...]", ou seja, traz uma proposta de autonomia e de descentralização do processo para as escolas, com vistas a uma participação mais democrática, porém não estabelece mecanismos que possam pressionar o avanço de ações viabilizadoras de um tempo possível para mudanças (ROCHA, 2008; SILVA, 2011). Corrobora Oliveira (2014) que o poder de decisão compartilhado aumenta as possibilidades de participação, mas também, como pano de fundo, presta-se aos objetivos de responsabilização da escola pelo sucesso e fracasso e de desresponsabilização do Estado.

No entanto, segundo aponta Medeiros (2008), quando o diretor representa de fato seus pares e sendo isto institucionalizado, com ações concretas e articuladas com o pedagógico, todos os envolvidos sentem-se pertencentes ao grupo, valorizam as relações e defendem os interesses coletivos, sempre apoiando o diretor. Tanto que, de 2013 a 2015, menciona o diretor: [...] nos 2 últimos anos foi eleito diretor geral do campus.

A eleição do diretor para o campus ocorreu via processo eleitoral, em 2013. Foi o primeiro processo de eleição que aconteceu no contexto da escola, devido a sua abertura, em 2010, quando o diretor foi indicado pelo reitor. Essa eleição do diretor é histórica, pois desde a origem dessa instituição denominada o Colégio das Fábricas (BELCHIOR, 1993) até os então Centros Federais de Educação Técnica - CEFET's (CUNHA, 2005).

De janeiro a março de 2015, período em que esta pesquisa foi realizada, foi o último semestre do mandato de dois anos do então diretor que participou desta pesquisa. Houve 
nova eleição, e o diretor em exercício se candidatou, juntamente com outro docente, o qual teve maior número de votos, sendo eleito e entrando em exercício no segundo semestre de 2015. Os atores que participaram desse processo foram: os estudantes, o pessoal técnicoadministrativo e os docentes.

Segundo Lima (2014, p. 1074),

A conjugação de processos eleitorais democráticos, da colegialidade dos órgãos e da participação nos processos de decisão concorre para a transformação da escola num locus de produção de políticas, de orientações e de regras, de decisões e ações, à margem das quais não será possível a desalienação do trabalho escolar e a edificação de uma escola mais democrática e em permanente processo de aprofundamento da sua autonomia, pois uma escola mais democrática é, necessariamente, uma escola mais autónoma e com capacidade de autogoverno em vastas áreas.

Essa espécie de provimento para o exercício do cargo de diretor favorece, contribui para o fortalecimento da gestão escolar democrática (DOURADO, 2007). Longe de não considerar que em algumas escolas, ainda que exista o mecanismo de eleição direta, ocorre a influência política e até mesmo práticas clientelistas (FISCHER; GUIMARÃES, 2016). Portanto, a gestão democrática das escolas está associada à existência, em maior ou menor grau, de estruturas organizacionais, procedimento e regras democráticas. ocorre, é comum a crítica ao formalismo da democracia, à sua tendência para se fixar em métodos, regras e rituais, frequentemente usados pelos atores iniciados e pelas elites para dificultar a participação dos outros. (LIMA, 2014, p. 10741075).

Destaca-se, portanto, que embora pareça romântico considerar o papel do diretor como fator que favorece o andamento do processo pedagógico e administrativo, de acordo com o contexto escolar isso pode ser uma realidade. $\mathrm{O}$ diretor está envolvido num fenômeno sistêmico, inter-relacionados e dependente de outros componentes, o que requer "habilidades interpessoais tais como de mediação de conflitos, liderança, articulação com a comunidade." (FISCHER; GUIMARÃES, 2016, p. 1820).

No caso do diretor deste trabalho, é um docente nomeado por seus pares, conforme ampara o Decreto no 6.986/2009 (BRASIL, 2009).

[...] enfim, democratizar a gestão da escola é uma escolha que tem consequências imediatas na atuação do diretor, que deve deixar de ser autoridade única e também o administrador burocrático, que se preocupa apenas com suprimento de recursos humanos e materiais, manutenção do prédio e preenchimento de papéis. $\mathrm{Na}$ proposta participativa, o diretor passa a ser o condutor do projeto pedagógico da escola, priorizando as questões pedagógicas, construindo o trabalho coletivo; enfim, o diretor é o grande articulador das ações de todos os segmentos na comunidade escolar (SILVA, 2011, p. 78).

A instituição pública da rede federal de ensino profissional e tecnológico, contexto desta pesquisa, apresenta elementos que contribuem para o processo de gestão democrática: a eleição 
do diretor; o conselho escolar; a construção do projeto político-pedagógico deve buscar "desenvolver a educação profissional e tecnológica como processo educativo e investigativo de geração e adaptação de soluções técnicas e tecnológicas às demandas sociais e peculiares regionais" (BRASIL, 2008). Visto que, as metas e os objetivos educacionais traçados pela comunidade escolar, na gestão são transformados em ações.

Cabe ao diretor promover a prática de bom relacionamento interpessoal e comunicação entre todas as pessoas da escola, estabelecendo canais de comunicação positivos na comunidade escolar. É um auxiliador na interpretação de significados das comunicações praticadas na comunidade escolar, fazendo-as convergir para os objetivos educacionais (LÜCK, 2009).

Assim, as decisões que forem tomadas de maneira participativa devem ser compreendidas a partir da descentralização das atividades administrativas e não da descentralização política, pois esta última é carregada de controle. Sendo assim, refletir sobre a descentralização política não basta; deve-se considerar com propriedade o que Santos Filho (1998) menciona sobre a descentralização das atividades administrativas, estendida à escola. Quando o poder decisório dentro da instituição é resultado da descentralização das atividades técnicas, as dinâmicas das decisões ocorrem de maneira mais ágil, flexível e efetiva. Quando isso acontece na escola, os principais efeitos são a criação de novas estruturas, responsabilização e mudanças.

A participação na tomada de decisão coletiva emerge como o elemento principal da gestão democrática das escolas (LIMA, 2014). Embora a gestão democrática represente uma conquista para as escolas, tal dispositivo tem implicado mais exigência que afeta a escola e, diretamente, a profissionalização docente. Conforme pontua Oliveira (2008, p. 35):

Os professores
encontram-se, portanto,
diante de uma nova
ambivalência: por um
lado, as formas mais
flexíveis e autônomas de
organização do trabalho
lhes trazem ganhos de
autonomia e maior
controle sobre suas
atividades; por outro lado,
essa mesma organização
lhes retira poder e

controle como grupo profissional, à medida que também atribui autonomia aos demais sujeitos que participam da escola e do sistema, com o poder de cobrar e exigir prestação de contas do que é realizado no espaço que, outrora, era de estrito domínio profissional.

Na pesquisa realizada por Falcão (2011), a participação da comunidade escolar nas decisões sobre o destino dos recursos financeiros, ainda que limitados, caracteriza de certa forma a descentralização. Porém na escola pesquisada a descentralização dos recursos financeiros não foi conduzida de maneira a contar com a participação dos agentes envolvidos com a escola, visto que a descentralização estava permeada por princípios da racionalidade técnica instrumental, dos pressupostos da administração e não de uma política pedagógica e educacional.

Por isso, é importante compreender que a "escola democrática é aquela em que os seus participantes estão coletivamente organizados e compromissados com a promoção de educação de qualidade para todos" (LÜCK, 2009, p. 69). E, para que isso aconteça, aponta a autora que o diretor precisa atuar no contexto escolar e desenvolver seu papel, contemplando aspectos essenciais da gestão democrática e participativa, abordada também na LDB no 9.394/96 (BRASIL, 1996).

A concepção do diretor sobre a educação desenvolvida na escola certamente influenciará o desenvolvimento de seu papel. Segundo Paro (2007, p. 100), "uma das formas de aferir as perspectivas democráticas da atual escola pública fundamental é examinar a situação atual em que se encontram os mecanismos de ação coletiva de que ela dispõe [...]." Complementa Garcia et al. (2016, p. 89) que a gestão democrática deve ser vista sob o prisma da legislação, dentre elas a LDB, e "a partir da participação efetiva de todos os atores da unidade escolar." Trata-se de um sistema, que não é criado e conduzido somente pela imposição da legislação, mas sim construído a partir da participação efetiva de todos os atores da unidade escolar.

A participação é um processo que se constrói no interior da escola. É no coletivo que se dá a construção da participação, e entende-se que o processo esta em construção. Percebe-se 
que a atuação dos estudantes é muita tímida, visto que, na fala do diretor,

[...] nós estamos tentando
fazer de maneira que
envolva mais os
estudantes,
fortaleceria e daria uma
conotação política, porque
o estudante teria que
aprender a falar com os
estudantes, os estudantes
se sentiriam responsáveis
e motivados para poder
apresentar a dificuldade
dele, o setor pedagógico
atuaria (DIRETOR_R,
2015).

Realmente, a participação precisa ser estimulada pelo diretor e docentes. A comunidade escolar necessita compreender que uma escola democrática conta com a participação atuante e viva. Para Paro (2000, p. 149), "a escola se pauta por relações que dizem respeito à forma pela qual os homens tomam consciência da própria realidade concreta".

As ações do diretor são fundamentais e constituintes dos ambientes coletivos de aprendizagem, como aponta a pesquisa desenvolvida com diretor, docentes e estudantes numa instituição federal de ensino profissional e tecnológico da Paraíba. Os elementos que contribuem para esse ambiente de aprendizagem são: a gestão democrática, a participação, o compromisso, a responsabilidade, o enfrentamento de desafios, a postura ética e o reconhecimento do potencial humano (ARAÚJO, 2013).

Complementa Bispo (2011) pontuando elemento essencial para o funcionamento efetivo de uma sociedade totalmente democrática: participação do maior número possível de cidadãos nas decisões, em diversas esferas da vida.

Os resultados da pesquisa desenvolvida por Santos (2015), tendo como objeto de estudo cinco escolas de educação profissional, indicam que a gestão democrática resulta de princípios como: a autogestão, a auto-organização, a participação efetiva e a inserção na coletividade que busca compreender o ambiente educativo para dar o tom à intencionalidade pedagógica específica, desejada e almejada. Preocupar-se com o pedagógico implica também docentes preparados para desenvolver e envolver-se nas atividades da escola, a formação continuada é estratégica para melhoria do desempenho profissional (FISCHER; GUIMARÃES, 2016; GALVÃO; SADOYAMA, 2017). Essa questão também é contemplada na fala do diretor, sujeito da pesquisa:

[...] devido muitas vezes o próprio entendimento do docente em relação às atividades que ele vai exercer, a falta de formação pedagógica. Para isso, nós precisamos deste entrosamento (DIRETOR_R, 2015).

Sabe-se, portanto, que o trabalho coletivamente organizado possibilita superar as contradições, conforme evidencia a pesquisa de Neto e Castro (2011) realizada em sete escolas, no ensino médio, de três municípios do estado do Rio Grande do Norte (Natal, Mossoró e Caicó).

Entretanto, as escolas de ensino médio que compuseram a pesquisa, no que concerne à sua gestão, contraditoriamente, vivenciam, nesses últimos anos, uma situação de perplexidade, visto que convivem, no mesmo espaço, com orientações situadas em polos contraditórios. O conflito se estabelece na medida em que esses profissionais, como afirmam os entrevistados, são desafiados a trabalhar com dois mecanismos distintos de gestão: o projeto políticopedagógico - concebido no âmbito da escola, embora com limitações, e que estaria, pelas suas características

teoricamente, mais alinhado a uma vertente de gestão democrática - e o Plano de Desenvolvimento da Escola (PDE da Escola) concebido com base em regras e orientações elaboradas por agentes externos à escola e que 
devem ser seguidas, sem muito espaço, para uma atuação dos sujeitos escolares. (NETO; CASTRO, 2011, p. 766).

São ações pautadas nos princípios de gestão escolar democrática que contribuem para mudanças de paradigmas:

o gestor escolar lida, hoje, com desafios decorrentes da mudança dos paradigmas sociais, econômicos e políticos, que pautam uma nova forma de pensar e fazer a gestão da escola. Descentralização, valorização do contexto, autonomia, abertura para a comunidade, trabalho em equipe, entre outras, são expressões que fazem parte das novas necessidades de ação colocadas por uma gestão que se deseja democrática (VIEIRA; ALMEIDA; ALONSO, 2003, p. 85).

Por isso, a importância destacada por Fraga (2009, p, 167),

[...] com essa possibilidade de mostração do fenômeno é que o agente precisa estar permanentemente sintonizado na gestão, se é que ele pretende compreender os problemas como eles realmente são, e não substituí-los por suas representações. Esse cuidado exige convívio intenso, cotidiano, em busca do bem comum.

Nessa perspectiva, o diretor deve compreender quais os objetivos educacionais que pretende, assim como os docentes, pois é na busca de objetivos comuns que se concretiza uma gestão escolar democrática.

$\begin{array}{llr}\text { À medida que os } & \text { os } \\ \text { problemas } & & \text { vão } \\ \text { aparecendo, vamos nos } & \text { nos } \\ \text { reunindo } & \text { com } & a s \\ \text { coordenações. Existe uma }\end{array}$

sequência, quem lida com

o docente são os

coordenadores gerais,

depois o gerente

educacional, e depois a

direção. A gerência

educacional tem

subordinada na hierarquia

o serviço sócio-pedagógico

e o serviço de apoio ao

ensino e de apoio escolar

(DIRETOR_R, 2015).

Quando isso acontece de modo acrítico é o que Paro (2010, p. 131) denomina: "deterioração das atividades no interior da escola". O diretor é o representante dos anseios da comunidade escolar; a tomada de decisão é coletiva e as relações na gestão escolar democrática devem ser horizontalizadas.

O poder de decidir, participando

democraticamente e com os outros nos respectivos processos de tomada das decisões representa o âmago da democracia e, consequentemente, sem participação na decisão não é possível conceber uma gestão democrática das escolas na perspectiva do seu autogoverno. (LIMA, 2014, p. 1072).

É com consciência que a tomada de decisão nas ações da escola determina o planejamento das atividades no interior do contexto escolar (GALVÃO; SADOYAMA, 2017; BASTOS; SANTOS, 2018).

\section{CONSIDERAÇÕES POSSÍVEIS}

A partir do objetivo proposto, com o estudo desenvolvido tornou-se possível analisar como o diretor da instituição pública federal de ensino profissional e tecnológica compreende a gestão escolar. Evidencia-se que a gestão escolar tem a preocupação com o processo de ensino e aprendizagem, embora não exista ainda o projeto político-pedagógico, documento fundamental que retrata a identidade da escola, que está em construção.

Embora a formação do diretor seja na área de engenharia, ele complementou sua formação com o curso de formação pedagógica, 
propiciado pela formação continuada. A LDB no 9.394/96 dispõe em seu art. 64 aponta que:

[...] a formação de profissionais de educação para administração, planejamento, inspeção, supervisão e orientação educacional para a educação básica será feita em cursos de graduação em pedagogia ou em nível de pós-graduação, a critério da instituição de ensino, garantida, nesta formação, a base comum nacional (BRASIL, 1996).

Portanto a formação pedagógica é uma formação necessária para todo docente, pois para se relacionar com o estudante $e$ desencadear $\mathrm{o}$ processo de ensino e aprendizagem o docente precisa conhecer as metodologias e didáticas. A formação pedagógica proporciona aos docentes sem licenciaturas base de conteúdos pedagógicos, fundamentais para o exercício da profissão.

Todavia é possível compreender que a concepção que o diretor tem sobre a gestão escolar faz que ele mobilize a comunidade escolar. A participação democrática da comunidade escolar, do coletivo organizado deve ser promovida pelo diretor (FORMIGA, 2007).

O comprometimento é apontado como um princípio da gestão escolar, mas também um desafio a ser superado. É possível ainda compreender como aspectos essenciais para potencializar o processo de gestão escolar democrática alguns elementos como: eleição de diretor e Conselho de Campus. A eleição do diretor já é um processo de que toda a comunidade participa. E o Conselho de Campus ainda está em fase de elaboração, sendo um dos elementos característicos de uma gestão escolar democrática, que tendo a participação crítica e responsável de toda a comunidade se vislumbra como um belo processo de fortalecimento democrático.

Portanto percebe-se que a gestão escolar não é compreendida como um processo acabado, mas em construção. As ações pedagógicas avançaram no contexto escolar, mas ainda precisam ser aprimoradas.
AGUIAR, M. A. da S. Gestão da educação básica e o fortalecimento dos Conselhos Escolares. Educar em Revista, Curitiba, n. 31, p. 129-144, 2008. Disponivel em: https://doi.org/10.1590/S010440602008000100009. Acesso em: 28 dez. 2015.

ARAÚJO, M. S. V. de. Elementos constituintes de aprendizagem para uma gestão escolar aprendente no Instituto Federal de Educação, Ciência e Tecnologia da Paraíba - Campus Cabedelo. 2013. 107 f. Dissertação (Mestrado em Gestão) - Universidade Federal da Paraíba, João Pessoa - PB. Disponível em: http://tede.biblioteca.ufpb.br:8080/handle/tede/ 5886. Acesso em: 30 jul. 2015.

BASTOS, M. S.; SANTOS, L. D. N. dos. Concepções e práticas acerca da formação continuada e o papel da gestão escolar: narrativas de professoras. Revista Educação Por Escrito, Porto Alegre, v. 9, n. 1, p. 82-101, jan./jun. 2018. Disponível em: https://doi.org/10.15448/21798435.1.27231. Acesso em: 28 fev. 2019.

BELCHIOR, E. de O. O Colégio Real de Fábricas do Rio de Janeiro. Revista do IHGB, Rio de Janeiro, v. 154, n. 380, p. 7-20, jul./set. 1993. Disponível em: http://www.ihgb.org.br/rihgb.php?s=p. Acesso em: 19 jun. 2015.

BISPO, V. P. Democracia e discurso democrático na gestão escolar: estudo de uma escola de aplicação. 2011. 282 f. Tese (Doutorado em Educação) - Faculdade de Educação, Universidade Estadual de Campinas, Campinas SP. Disponível em: http://www.bibliotecadigital.unicamp.br/docume $\mathrm{nt} /$ ?code $=000839677 \& \mathrm{fd}=\mathrm{y}$. Acesso em: $30 \mathrm{jul}$. 2015.

BRASIL. Decreto no 6.986, de 20 de outubro de 2009. Regulamenta os arts. 11,12 e 13 da Lei

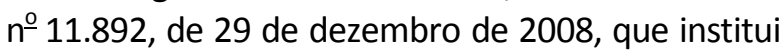
a Rede Federal de Educação Profissional, Científica e Tecnológica e cria os Institutos Federais de Educação, Ciência e Tecnologia, para disciplinar o processo de escolha de dirigentes no âmbito destes Institutos. Diário Oficial da União, Brasília, DF, 20 out. 2009. Disponível em: http://www.planalto.gov.br/ccivil 03/ ato20072010/2009/Decreto/D6986.htm. Acesso em: 19 jan. 2016.

\section{REFERÊNCIAS}


BRASIL. Lei no 9.394, de 20 de dezembro de 1996. Estabelece as Diretrizes e Bases da Educação Nacional. Diário Oficial da União, Brasília, DF, 23 dez. $\quad 1996 . \quad$ Disponível em: http://www.planalto.gov.br/ccivil 03/leis/19394 htm. Acesso em: 30 abr. 2019.

BRASIL. Lei no 11.892, de 29 de dezembro de 2008. Institui a Rede Federal de Educação Profissional, Científica e Tecnológica, cria os Institutos Federais de Educação, Ciência e Tecnologia, e dá outras providências. Diário Oficial da União, Brasília, DF, 30 dez. 2008. Disponível em: http://www.planalto.gov.br/ccivil 03/ ato20072010/2008/lei/l11892.htm. Acesso em: 19 jan. 2016.

BRASIL. Plano Nacional de Educação PNE 20142024 linha de Base. Brasília, DF, 2015. Disponível em:

http://portal.inep.gov.br/documents/186968/48 5745/Plano+Nacional+de+Educa\%C3\%A7\%C3\%A 3o+PNE+2014-2024++Linha+de+Base/c2ddOfaa7227-40ee-a520-12c6fc77700f?version=1.1. Acesso em: 30 abr. 2019.

CARVALHO, E. J. G. de. Reformas na administração educacional: uma análise comparada entre Brasil e Portugal. Revista Portuguesa de Educação, Braga, v. 27, n. 1, p. 2954, jun. 2014. Disponível em: https://doi.org/10.21814/rpe.4296. Acesso em: 24 jul. 2015.

CORREIA, M. de A. As representações de gestão democrática dos dirigentes de escolas públicas: um estudo na rede municipal do Recife. 2011. 88 f. Dissertação (Mestrado em Educação) Universidade Federal de Pernambuco, Recife PE. Disponível em: http://hdl.handle.net/123456789/4878. Acesso em: 30 jul. 2015.

CUNHA, L. A. 0 ensino profissional na erradicação do industrialismo. São Paulo: Editora UNESP, Brasília, DF: Flacso, 2005.

DIRETOR R_2015. Entrevista. Birigui. São Paulo, 06 abril, 2015.

DOURADO, L. F. Políticas e gestão da educação básica no Brasil: limites e perspectivas. Educação \& Sociedade, Campinas, v. 28, n. 100, p. 921-
946, out. 2007. Disponível em: https://doi.org/10.1590/S0101-

73302007000300014. Acesso em: 29 dez. 2015.

FALCÃO, M. S. M. A gestão democrática dos recursos financeiros nas escolas do município de Dourados (MS) 2005-2008. 2011. 350 f. Tese (Doutorado em Educação) - Faculdade de Educação, Universidade de São Paulo, São Paulo - SP. Disponível em: http://www.teses.usp.br/teses/disponiveis/48/4 8134/tde-14052012-125403/. Acesso em: 30 jul. 2015.

FÉLIX, M. de F. C. Administração escolar: um problema educativo ou empresarial. São Paulo: Cortez, 1986.

FERNANDES, F. S.; CAMPOS, M. M. Gestão da educação infantil: um balanço de literatura. Educação em Revista, Belo Horizonte, v. 31, n. 1, p. 139-167, jan./mar. 2015. Disponível em: https://doi.org/10.1590/0102-4698111747.

Acesso em: 24 jul. 2015.

FISCHER, S. D.; GUIMARÃES, M. C. L. Gestão autônoma e democrática: um estudo nas escolas públicas municipais do estado de Santa Catarina. Revista Ibero-Americana de Estudos em Educação, v. 11, n. 4, p. 1814-1834, 2016. Disponível em: https://doi.org/10.21723/riaee.v11.n4.6133.

Acesso em: 28 fev. 2019.

FORMIGA, M. G. F. 0 administrativo e o pedagógico na gestão escolar. 2007. 138 f. Dissertação (Mestrado em Educação), Faculdade de Educação e Letras, Universidade Metodista de São Paulo, São Bernardo do Campo - SP. Disponível em: http://ibict.metodista.br/tedeSimplificado/tde b usca/arquivo.php?codArquivo $=618$. Acesso em: 30 jul. 2015.

FRAGA, V. F. Gestão pela formação humana: uma abordagem fenomenológica. Barueri: Manole, 2009.

GALVÃO, E. A.; SOUSA, M. F. de. As escolas técnicas do SUS: que projetos políticopedagógicos as sustentam? Physis Revista de Saúde Coletiva, Rio de Janeiro, v. 22, n. 3, p. 1159-1189, 2012. Disponível em: 
https://doi.org/10.1590/S0103733120120003000

17. Acesso em: 15 out. 2015.

GALVÃO, L. L. C.; SADOYAMA, A. S. P. Avaliação da expectativa e percepção da qualidade dos serviços educacionais na perspectiva de gestores, professores e estudantes de um instituto federal do estado de Minas Gerais (MG). Revista Educação a Distância e Práticas Educativas Comunicacionais e Interculturais (EDaPECI), São Cristovão-SE, v. 17, n. 2, p. 131-143, 2017. Disponível em: https://seer.ufs.br/index.php/edapeci/article/vie w/6275/pdf. Acesso em: 28 fev. 2019.

GADOTTI, M. Autonomia da escola: princípios e propostas. São Paulo: Cortez, 1997.

GONÇALVES, F. O.; FRANÇA, M. T. A. Eficiência na provisão de educação pública municipal: uma análise em três estágios dos municípios brasileiros. Estudos Econômicos, São Paulo, v. 43, n. 2, p. 271-299, jun. 2013. Disponível em: https://doi.org/10.1590/S0101416120130002000 03. Acesso em: 24 jul. 2015.

GARCIA, P. S.; PREARO, L. C.; ROMERO, M. C.; BASSI, M. S. Diretores de escola e gestão democrática na região do $A B C$ paulista. Política e Gestão Educacional, Araraquara, v. 20, n. 1, p. 87-107, jan./abr. 2016. Disponível em: https://doi.org/10.22633/rpge.v20.n1.2016.9394. Acesso em: 28 fev. 2019.

LIMA, L. A Gestão Democrática das Escolas: do autogoverno à ascensão de uma pós-democracia gestionária? Educação \& Sociedade, Campinas, v. 35, n. 129, p. 1067-1083, dez. 2014. Disponível em: $\quad$ https://doi.org/10.1590/ES010173302014142170. Acesso em: 16 dez. 2015.

LÜCK, H. Dimensões de gestão escolar e suas competências. Curitiba: Positivo, 2009.

LÜDKE, M.; ANDRÉ. M. Pesquisa em Educação: abordagens qualitativas. São Paulo: EPU, 1986.

MAIA, G. Z. A. As publicações da ANPAE e a trajetória do conhecimento em administração da educação no Brasil. Revista Brasileira de Política e Administração da Educação, Goiânia, v. 24, n. 1, p. 31-50, jan./abr. 2008. Disponível em: http://www.anpae.org.br/website/documentos/ estudos/estudos 03.pdf. Acesso em: 19 out. 2015.

MARTINS, A. M.; SOUSA, S. Z. A produção científica sobre avaliação educacional e gestão de sistemas e de escolas: o campo da questão entre 2000 e 2008. Ensaio: Avaliação e Políticas Públicas em Educação, Rio de Janeiro, v. 20, n. 74, p. 9-26, jan./mar. 2012. Disponível em: https://doi.org/10.1590/S0104403620120001000 02. Acesso em: 24 jul. 2015.

MEDEIROS, S. S. M. Gestão participativa em educação: compasso e descompasso de uma experiência de democracia no espaço escolar. 2008. 150f. Dissertação (Mestrado em Desenvolvimento Regional, Cultura e Representações) - Universidade Federal do Rio Grande do Norte, Natal - RN. Disponível em: http://repositorio.ufrn.br:8080/jspui/handle/123 456789/13570. Acesso em: 30 jul. 2015.

MENEZES, S. B. de. Modelos de gestão escolar no estado do Amazonas: entre o dito e o feito. 2009. 178 f. Dissertação (Mestrado em Educação) - Universidade Federal do Amazonas, Manaus AM. Disponível em: http://tede.ufam.edu.br/handle/tede/3214.

Acesso em: 30 jul. 2015.

NETO, A. C.; CASTRO, A. M. D. A. Gestão escolar em instituições de ensino médio: entre a gestão democrática e a gerencial. Educação \& Sociedade, Campinas, v. 32 , n. 116 , p. 745-770, set. 2011. Disponível em: https://doi.org/10.1590/S0101733020110003000 08. Acesso em: 24 jul. 2015.

OLIVEIRA, D. A. O trabalho docente na América Latina: identidade e profissionalização. Revista Retratos da Escola, Brasília, v. 2, n. 2-3, p. 29-39, jan./dez. 2008. Disponível em: http://www.esforce.org.br/index.php/semestral/ article/view/122/225. Acesso em: $28 \mathrm{dez} .2015$.

OLIVEIRA, T. C. de. Gestão escolar no estado de São Paulo: perspectiva democrática ou modelo gerencial? Uma análise a partir do relatório dos estudos do SARESP (2010 a 2012). 2014. $148 \mathrm{f}$. Dissertação (Mestrado em Educação) - Faculdade de Filosofia e Ciências, Universidade Estadual Paulista, Marília - SP. Disponível em: http://hdl.handle.net/11449/110476. Acesso em: 30 jul. 2015. 
PARENTE, J. M. Gestão escolar no contexto gerencialista: o papel do diretor escolar. Roteiro, Joaçaba, v. 42, n. 2, p. 259-280, 2017. Disponível em: $\quad$ https://doi.org/10.18593/r.v42i2.12535. Acesso em: 28 fev. 2019.

PARO, V. H. Administração escolar: introdução crítica. São Paulo: Cortez, 2000.

PARO, V. H. A educação, a política e a administração: reflexões sobre a prática do diretor de escola. Educação e Pesquisa, São Paulo, v. 36, n. 3, p. 763-778, dez. 2010. Disponível em: https://doi.org/10.1590/S151797022010000300008. Acesso em: 24 jul. 2015.

PARO, V. H. Gestão escolar: democracia e qualidade de ensino. São Paulo: Ática, 2007.

PIMENTA, S.; GHEDIN, E. (Org.). Professor reflexivo no Brasil. São Paulo: Cortez, 2006.

PIMENTEL, M. G. O professor em construção. Campinas: Papirus, 1998.

ROCHA, M. L. Inclusão ou exclusão? Produção de subjetividade nas práticas de formação. Psicologia em Estudos, Maringá, v. 13, n. 3, p. 477-484, set. 2008. Disponível em: https://doi.org/10.1590/S1413737220080003000 08. Acesso em: 25 jul. 2015.

SANTOS, L. R. dos. Gestão democrática e participação na educação profissional agroecológica do MST (PR): limites e possibilidades de uma educação emancipatória. 2015. 142 f. Dissertação (Mestrado em Educação) - Faculdade de Filosofia e Ciências, Universidade Estadual Paulista, Marília - SP. Disponível em: http://www.athena.biblioteca.unesp.br/exlibris/b d/cathedra/25-06-2015/000839330.pdf. Acesso em: 30 jul. 2015.

SANTOS FILHO, J. C. dos. Democracia institucional na escola: discussão teórica. Revista de Administração Educacional, Recife, v. 1, n. 2, p. 41-102, jan./jun. 1998.

SÃO PAULO. Resolução no 27, de 11 de março de 2014. Estabelece as diretrizes para a composição e atribuições do Conselho de Campus do Instituto Federal de Educação, Ciência e Tecnologia de São Paulo.
$<$ http://www.ifsp.edu.br/index.php/arquivos/cat egory/417-resolucoes-2014.html?start=100>.

Acesso em: 28 dez. 2015.

SCHÖN, D. Formar professores como profissionais reflexivos. In: NÓVOA, A. (Orgs.). Os professores e a sua formação. Lisboa: Dom Quixote, 1997, p. 77- 92.

SILVA, M. P. S. A re-configuração das atribuições do diretor escolar com a instauração do regime de gestão democrática da escola. 2011. 115 f. Dissertação (Mestrado em Educação) - Faculdade de Filosofia e Ciências, Universidade Estadual Paulista, Marília - SP. Disponível em: http://hdl.handle.net/11449/96354. Acesso em: 30 jul. 2015.

VIEIRA, A. T.; ALMEIDA, M. E. B. de; ALONSO, M. (orgs). Gestão Educacional e Tecnologia. São Paulo: Avercamp, 2003. 